TITLE:

\title{
Levels and profiles of long-chain perfluorinated carboxylic acids in human breast milk and infant formulas in East Asia.
}

\section{AUTHOR(S):}

Fujii, Yukiko; Yan, Junxia; Harada, Kouji H; Hitomi, Toshiaki; Yang, Hyeran; Wang, Peiyu; Koizumi, Akio

\section{CITATION:}

Fujii, Yukiko ... [et al]. Levels and profiles of long-chain perfluorinated carboxylic acids in human breast milk and infant formulas in East Asia.. Chemosphere 2012, 86(3): 315-321

\section{ISSUE DATE:}

2012-01

URL:

http://hdl.handle.net/2433/152422

\section{RIGHT:}

(c) 2011 Elsevier Ltd.; この論文は出版社版でありません。引用の際には 出版社版をご確認ご利用ください。; This is not the published version. Please cite only the published version. 
1 Levels and profiles of long-chain perfluorinated carboxylic acids in human

2 breast milk and infant formulas in East Asia

3

4 Fujii Yukikoa,1, Junxia Yana,1, Kouji H. Harada ${ }^{a}$, Toshiaki Hitomia, Hyeran

5 Yanga, Peiyu Wangb, Akio Koizumia,*

6

7 aDepartment of Health and Environmental Sciences, Kyoto University

8 Graduate School of Medicine, Yoshida, Kyoto 606-8501, Japan

9 bDepartment of Social Medicine and Health Education, School of Public

10 Health, Peking University, Haidian, Beijing 100083, PR China

12 1These authors contributed equally to this study.

14 *Correspondence to: Akio Koizumi M.D., Ph.D.

15 Department of Health and Environmental Sciences, Kyoto University

16 Graduate School of Medicine, Yoshida Konoe, Sakyo, Kyoto 606-8501, Japan

17 Tel: +81-75-753-4456; Fax: +81-75-753-4458

18 E-mail: koizumi.akio.5v@kyoto-u.ac.jp 


\section{Abstract}

In this study, 90 human breast milk samples collected from Japan, Korea, and China were analyzed for perfluorooctanoic acid (PFOA) (C8), perfluorononanoic acid (PFNA) (C9), perfluorodecanoic acid (PFDA) (C10), perfluoroundecanoic acid (PFUnDA) (C11), perfluorododecanoic acid (PFDoDA) (C12), and perfluorotridecanoic acid (PFTrDA) (C13). In addition, infant formulas $(n=9)$ obtained from retail stores in China and Japan were analyzed. PFOA was the predominant compound and was detected in more than $60 \%$ of samples in all three countries. The PFOA, PFNA, PFDA, and PFUnDA levels in Japan were significantly higher than those in Korea and China $(p<0.05)$. The PFTrDA level was highest in Korea $(p<0.05)$. The median PFOA concentrations were $89 \mathrm{pg} \mathrm{mL}^{-1}$ (48\% of total perfluorinated carboxylic acids (PFCAs) (C8-C13)) in Japan, $62 \mathrm{pg} \mathrm{mL}^{-1}$ (54\%) in Korea, and $51 \mathrm{pg} \mathrm{mL}^{-1}(61 \%)$ in China. The remaining $\Sigma$ PFCAs (C9-C13) were $95 \mathrm{pg}$ $\mathrm{mL}^{-1}$ in Japan, $52 \mathrm{pg} \mathrm{mL}^{-1}$ in Korea, and $33 \mathrm{pg} \mathrm{mL}^{-1}$ in China. Among the long-chain PFCAs, odd-numbered PFCAs were more frequently detected than even-numbered PFCAs, except for PFDA in Japan. There were no evident correlations between the mother's demographic factors and the PFCA concentrations. PFOA, PFNA, and PFDA were frequently detected in both Japan and China, but there were no significant differences between the two countries. The total PFCA concentrations in the infant formulas were lower than those in the breast milk samples in Japan $(p<0.05)$, but not in China ( $p>0.05$ ). In conclusion, various PFCAs were detected in human breast 
44 milk samples from East Asian countries. Further studies are needed to

45 evaluate the exposure to long-chain PFCAs and the health risks in infants.

46 Keywords:

47 Human breast milk; perfluorinated carboxylic acids; Japan; Korea; China;

$48 \quad$ Asia 


\section{Introduction}

Perfluorinated compounds ( $\mathrm{PFCs}$ ) comprise a large group of man-made fluorinated organic chemicals. They have been produced since the 1950s and are used for various industrial and consumer-related applications, such as food packaging materials, protective coatings for textiles, carpets, papers, and surfactants (Key et al., 1997). During the last decade, PFCs such as perfluorooctane sulfonate (PFOS) and perfluorooctanoic acid (PFOA) have been found at considerable levels in various biota samples including the liver and tissues, and especially human blood and serum, worldwide (Fromme et al., 2009).

The toxic effects of PFOS and PFOA have been investigated in animal studies. Prenatal as well as postnatal toxic effects of PFOA and PFOS were observed in rats and mice, including increased liver weights, growth lags, and delayed development. The reproductive and developmental toxicities of these chemicals toward humans are of particular concern (Lau et al., 2004). Several epidemiological investigations have raised concerns regarding the developmental effects of PFOS and PFOA on children, such as low birth weights (Steenland et al., 2010).

In the Stockholm Convention on Persistent Organic Pollutants, PFOS is listed in Annex B (Wang et al., 2009). Fluoropolymer manufacturers have also committed themselves to voluntarily reducing PFOA emissions under a stewardship program by the US EPA (EPA, 2006). The temporal trends in serum levels have revealed decreases in the serum levels of both PFOA and 
PFOS in the United States, Norway, and Japan since 2000 (Olsen et al., 2007; Harada and Koizumi, 2009; Haug et al., 2009; Harada et al., 2010).

In contrast to PFOS and PFOA, little information is available for perfluorinated carboxylic acids (PFCAs) with longer chains than PFOA. The emissions of perfluorononanoic acid (PFNA) and perfluoroundecanoic acid (PFUnDA) were 25 and 7 metric tons, respectively, in 2000 (Prevedouros et al., 2006). A modeling study indicated that these PFCAs could also have been emitted from precursor compounds, such as fluorotelomer alcohols (FTOHs), for decades (Van Zelm et al., 2008). Recent evidence suggests that the toxicological effects of PFCAs are strongly correlated with their chain lengths and functional groups (Upham et al., 1998; Matsubara et al., 2006; Wolf et al., 2008; Liao et al., 2009). Therefore, the effects of exposure to long-chain PFCAs need to be clarified, especially in infants.

Human breast milk and infant formulas are considered to be the main PFC exposure sources for infants during the lactation period. Indeed, contamination of PFCs in human breast milk has been reported in various studies from Asia (So et al., 2006; Tao et al., 2008; Nakata et al., 2009; Liu et al., 2010; Kim et al., 2011; Liu et al., 2011), the United States (Kuklenyik et al., 2004; Tao et al., 2008; von Ehrenstein et al., 2009), and Europe (Karrman et al., 2007; Bernsmann and Furst, 2008). However, the available data for PFCAs with longer chains than PFNA in human breast milk are limited, because of the low recoveries of long-chain PFCAs from human breast milk samples (Karrman et al., 2007). 
The aim of the present study was to investigate the current levels of long-chain PFCAs in human breast milk in East Asian countries, which were reported to show increasing trends for long-chain PFCAs in serum (Harada et al., 2011). Human breast milk samples collected from Japan, Korea, and China were analyzed for PFOA, PFNA, perfluorodecanoic acid (PFDA), PFUnDA, perfluorododecanoic acid (PFDoDA), and perfluorotridecanoic acid (PFTrDA) using an ion-pair extraction method (Hansen et al., 2001) with modifications. In addition, infant formulas from representative manufacturers in the Japanese and Chinese markets were analyzed for comparison with the PFCA concentrations in the breast milk samples from the same regions.

\section{Methods and Materials}

\subsection{Study population and sample information}

To evaluate the geographical differences in the PFCA levels in human breast milk, we selected 30 samples each from Japan, Korea, and China that were stored in the Human Specimen Bank of Kyoto University (Koizumi et al., 2005; Koizumi et al., 2009). For infant formulas, we obtained five products from five different companies in the Japanese market and four products from four different companies in the Chinese market. The main ingredients of these infant formulas were cow milk, cow milk-related products (milk whey protein, lactose, and casein), and edible oils (palm olein and soybean oil). A summary of the sample information is provided in Table 
Written informed consent was obtained from all the participants. The research protocol for the present study was reviewed and approved by the Ethics Committee of the Kyoto University Graduate School of Medicine on 14 November 2003 (E25).

\subsection{Standards and reagents}

Analytical standards for the PFCAs, ${ }^{13} \mathrm{C}_{4}$-labeled PFOA and ${ }^{13} \mathrm{C}_{5}$-labeled PFNA, were obtained from Wellington Laboratories (PFC-MXA, MPFOA, and MPFNA; Guelph, Ontario, Canada).

Methanol, acetone, dichloromethane (DCM), and hexane (purity: >99\%, pesticide analysis grade) were obtained from Kanto Chemicals (Tokyo, 130 Japan). Ethyl acetate (pesticide analysis grade), methyl $t$-butyl ether (MTBE, pesticide analysis grade), tetrabutylammonium hydrogen sulfate (TBA), sodium carbonate, sodium bicarbonate, and benzyl bromide were purchased from Wako Pure Chemicals (Osaka, Japan). Ultrapure water (Milli-Q ${ }^{\mathrm{TM}}$ Reference; Millipore, Billerica, MA) was used for all solutions. MTBE, DCM, and hexane were prefiltered through silica gel (Presep-C silica gel; Wako Pure Chemicals). Methanol, ethyl acetate, and acetone were distilled before use. Milli-Q water was filtered through an Oasis WAX column (Waters, Milford, MA). 


\subsection{Sample preparation and extraction}

Frozen human breast milk samples were thawed and returned to room temperature before extraction. A liquid-liquid and solid-phase extraction method was used to extract the PFCAs in the samples. Aliquots of breast milk (2 mL) together with an internal standard $\left({ }^{13} \mathrm{C}_{4}-\mathrm{PFOA}, 1 \mathrm{ng}\right)$ were placed in $15-\mathrm{mL}$ polypropylene sample tubes. Next, $2 \mathrm{~mL}$ of $0.5 \mathrm{M}$ TBA/0.25 $\mathrm{M}$ sodium carbonate buffer ( $\mathrm{pH}$ adjusted to 10 using $\mathrm{NaOH}$ ) and $2 \mathrm{~mL}$ of methanol were added to the samples and vortexed for $15 \mathrm{~s}$. After addition of $3 \mathrm{~mL}$ of MTBE, the samples were mixed again and centrifuged at 10,000 rpm for $5 \mathrm{~min}$. The supernatants were separated into new glass tubes. Another 3 mL of MTBE was added and the extraction was performed again. The combined sample extracts were dried under a gentle stream of nitrogen. Subsequently, each extract was dissolved in $4 \mathrm{~mL}$ of 1:1 MTBE/DCM and loaded onto a Presep-C silica gel column preconditioned with $45 \mathrm{~mL}$ of methanol and $4 \mathrm{~mL}$ of 1:1 MTBE/DCM on a vacuum manifold. The silica gel column was washed with $10 \mathrm{~mL}$ of hexane and $30 \mathrm{~mL}$ of ethyl acetate that had been prefiltered through another Presep-C silica gel column. The target fraction was eluted using $12 \mathrm{~mL}$ of acetone that had been prefiltered through an alumina column (Sep-Pak plus alumina N; Waters). The eluate was dried under a gentle stream of dry nitrogen. The residue was then redissolved in $100 \mu \mathrm{L}$ of $0.1 \mathrm{M}$ benzyl bromide/acetone solution and derivatized at $60^{\circ} \mathrm{C}$ for $1 \mathrm{~h}$. No further clean-up was conducted.

The infant formulas were dissolved in Milli-Q water according to the 
guidelines on the packages. Cow milk (4 mL), Milli-Q water $(2 \mathrm{~mL}$, procedural blank), and infant formulas $(2 \mathrm{~mL})$ were treated by the same procedure used for the human breast milk samples.

\subsection{Instrumental analysis}

The extracts were analyzed by gas chromatography-mass spectrometry (Agilent 6890GC/5973MSD; Agilent Technologies Japan Ltd., Tokyo, Japan) in the electron impact ionization mode. The PFCAs were separated on a J\&W DB-5MS column with a helium carrier gas $\left(1.5 \mathrm{~mL} \mathrm{~min}^{-1}\right)$. The splitless injection volume was $2 \mu \mathrm{L}$. The oven temperature was $70{ }^{\circ} \mathrm{C}$ for $2 \mathrm{~min}$ initially, and then ramped up to $280{ }^{\circ} \mathrm{C}$ at $20^{\circ} \mathrm{C} \min ^{-1}$. The monitored ions are listed in Table 2. Standard stock solutions $(2 \mu \mathrm{g} \mathrm{mL}-1)$ were diluted to seven working standard solutions $\left(4,2,1,0.8,0.4,0.2\right.$, and $\left.0.1 \mathrm{ng} \mathrm{mL}^{-1}\right)$ by serial dilutions in acetone. All the standard solutions were stored in a refrigerator at $4 \pm 2{ }^{\circ} \mathrm{C}$ for a maximum period of 3 months from the date of preparation.

The instrumental detection limits (IDLs) were defined as the mass of analyte producing a peak with a signal-to-noise ratio of 3 , and ranged from $0.5 \mathrm{pg}$ (PFUnDA, PFDoDA, and PFTrDA) to $0.2 \mathrm{pg}$ (other PFCAs).

\subsection{Quality assurance}

We used Milli-Q water as the procedural blank control. The average blank values $(n=6)$ were $20.5 \mathrm{pg} \mathrm{mL}^{-1}(\mathrm{PFOA}), 5.2 \mathrm{pg} \mathrm{mL}^{-1}$ (PFNA), and $7.1 \mathrm{pg} \mathrm{mL}^{-1}$ 
(PFDA). In the case of blank levels, the mean blank signal was subtracted from the calculated sample concentration only if the calculated sample concentration was three times higher than the blank concentration. If no signal was detected in the blank samples, the method detection limits (MDLs) were based on the IDLs and 2-mL milk samples. Using this method, we established that the MDLs ranged from 40 to $10 \mathrm{pg} \mathrm{mL}^{-1}$ (Table 2).

${ }^{13} \mathrm{C}_{4}$-PFOA was used as an internal standard for the PFCAs. ${ }^{13} \mathrm{C}_{5}$-PFNA was used to monitor the recovery of the internal standard. The recoveries of the PFCAs were examined by spiking $500 \mathrm{pg}$ of each standard compound into cow milk. The mean recoveries of PFOA, PFNA, PFDA, PFUnDA, PFDoDA, and PFTrDA were 104\%, 84\%, 109\%, 95\%, 92\%, and 97\%, respectively. Typical chromatograms of PFCAs obtained in this study are shown in Supplemental figure 1.

For quality assurance and quality control of our analytical methods and procedures in the analysis of PFCAs in the breast milk samples, we measured PFCAs in standard reference materials from the National Institute of Standards and Technology (Table 2). The PFCA values were comparable to those reported previously (Keller et al., 2010).

\subsection{Statistical analysis}

We calculated the percentages of detection of the PFCAs in each country, and determined the range, median, mean, standard deviation, geometric mean, and 90th percentile concentration. Concentrations below the MDL 
were replaced by half of the MDL for statistical analyses. Nonparametric

210 statistical tests were applied to assess the statistical significance of

211 differences between values. The Steel-Dwass test was used to compare

212 differences in the PFCA concentrations among different countries after the

213 Kruskal-Wallis test. Spearman's rank correlation analysis was used to

214 examine the relationships between the PFCA levels and the mother's age

215 and child's birth weight. The Mann-Whitney test was used to examine the

216 relationships between the PFCA levels and alcohol drinking and cigarette

217 smoking. The level of statistical significance was set at $p<0.05$. A factor

218 analysis was used to elucidate the number of potential factors of sources. The

219 analyses were conducted via a correlation matrix. Eigenvectors were

220 employed for the analysis when the eigenvalues were greater than 1.

221 Normalized varimax rotation was applied to these eigenvectors. The

222 statistical analyses were carried out using the software $\mathrm{JMP}^{\circledR} 4$ (SAS

223 Institute Inc., Cary, NC) or R Ver. 2.12.1. (Ihaka and Gentleman, 1996) for

224 the Steel-Dwass test.

\section{Results}

\subsection{PFCA concentrations in breast milk in Japan, Korea, and China}

The demographic characteristics of the participants are shown in Table 1. The participants in Korea were, on average, about 3 years older than those in Japan and China. The descriptive statistical data are summarized in 
232 than $60 \%$ of samples in all three Asian countries. The median concentration

233 of PFOA ranged from $51 \mathrm{pg} \mathrm{mL}^{-1}$ in China to $89 \mathrm{pg} \mathrm{mL}^{-1}$ in Japan. The PFOA 234 levels in Japan were significantly higher than those in Korea and China $(p<0.05$, Steel-Dwass test).

236 PFNA and PFUnDA were detected at comparable rates to PFOA in the 237 three countries. The levels of PFNA and PFUnDA were higher in Japan than 238 in Korea and China $(p<0.05$, Steel-Dwass test). PFDA was frequently 239 detected in Japan (67\%), but rarely detected in Korea (13\%) and China (13\%).

240 In Korea, half of the milk samples contained detectable levels of PFTrDA, 241 which was the highest among the three countries ( $p<0.05$, Steel-Dwass test). 242 PFDoDA was detected in few samples in the three Asian countries and there were no significant differences $(p>0.05)$. Regarding the total PFCAs in the 244 milk samples, PFOA accounted for 48\%, 54\%, and 61\% in Japan, Korea, and 245 China, respectively. Among the long-chain PFCAs, odd-numbered PFCAs 246 were more frequently detected than even־numbered PFCAs, except for PFDA 247 in Japan.

PFOA was only significantly correlated with PFNA ( $\rho$ coefficient: $>0.4)$

249 (Supplemental table 1). There were also significant correlations between PFNA and PFUnDA, PFDA and PFUnDA, and PFUnDA and PFTrDA $(\rho$ coefficients: >0.4). In general, the PFCA concentrations showed strong correlations between PFCAs of similar (i.e. adjacent) chain lengths. accounted for $43.3 \%$ and $19.0 \%$ of the total variance (with eigenvalues of $>1$ ), 
255

respectively (Table 4). After varimax rotation, F1 indicated higher eigenvectors for PFOA, PFNA, PFDA, and PFUnDA, while F2 had positive eigenvectors for PFUnDA and PFTrDA. The mean factor scores of each sampling site are also shown in Table 4. Although the F1 score was higher in Kyoto than in the other two sites ( $p<0.05$, Steel-Dwass test), there were no significant differences in the F2 scores among all the sampling sites ( $p>0.05$, Kruskal-Wallis test).

\subsection{PFCA concentrations in commercially available infant formulas in Japan} and China

The PFCA concentrations in the infant formulas are shown in Table 5. PFOA, PFNA, and PFDA were frequently detected in both Japan and China, but there were no significant differences between the two countries. PFUnDA was detected at $40.7 \mathrm{pg} \mathrm{mL}^{-1}$ in one sample in Japan. PFDoDA and PFTrDA were not detected in any of the formula samples. Compared with the breast milk samples, the PFOA levels were 4 -fold and 2 -fold lower in the formula samples in Japan and China, respectively. The total PFCA concentrations in the infant formulas were lower than those in the breast milk samples in Japan ( $p<0.05$, Kruskal-Wallis test), but not in China ( $p>0.05$, Kruskal-Wallis test).

3.3. Relationships between the PFCA levels and the participants' characteristics 
To evaluate the influence of the participants' characteristics on the PFCA concentrations in the human breast milk samples, Spearman's correlation analyses were performed (Supplemental table 2). PFDoDA was positively correlated with the mother's age in Korea $(p<0.05)$ and PFNA was negatively correlated the mother's age in China $(p<0.05)$. However, these correlations were not consistent among the three countries. In several epidemiological studies (Steenland et al., 2010), the PFC concentrations in the cord blood or maternal pregnancy serum were reported to be associated with the child birth weight. In our study subjects, the correlations between the PFCA concentrations and the child birth weights were not significant. The lactation period was also examined for correlations with PFCAs in the milk samples. PFDA was correlated with the lactation period in Japan $(p<0.05)$, but not in 290 Korea. Among the PFCAs, there were no clear trends in the correlation coefficients. Although consumption of fish was one of the sources of exposure to PFCAs, no significant associations were observed between the PFCA 293 levels in the milk samples and the fish intake $(p>0.05)$. Non-smoking mothers in Japan had relatively higher PFCAs levels than other mothers, but the difference was not significant $(p>0.05)$. The PFCA levels in the milk samples were compared between non-drinking mothers and other mothers. The PFTrDA and PFNA levels were lower in non-drinking mothers in Japan and Korea ( $p<0.05$, Mann-Whitney test). 
The tolerable daily intake (TDI) for PFOA was established to be $1500 \mathrm{ng} \mathrm{kg}$ body weight ${ }^{-1} \mathrm{~d}^{-1}$ by the Scientific Panel on Contaminants in the Food Chain requested by the European Food Safety Authority in 2008 0. The average breast milk consumption rate and body weight for 1-year-old infants were assumed to be $600 \mathrm{~g} \mathrm{~d}^{-1}$ and $7.3 \mathrm{~kg}$, respectively (Schecter, 1994). Based on these assumptions, the daily intakes of PFCAs by 1-year-old infants were estimated (Supplemental table 3). For the infant formulas, the calculated mean levels were only $0.1-0.2 \%$ of the TDI. Meanwhile, the calculated levels for the human breast milk samples (means: $0.3-0.5 \%$ of the TDI; 90th percentiles: $0.6-0.9 \%$ of the TDI) were higher than those for the infant formulas. As of 2011, there is no established TDI for PFCAs that are longer than PFOA.

\section{Discussion}

In the present study, we first demonstrated contamination of human breast milk with PFDoDA and PFTrDA in Asian countries. Simultaneously, we confirmed similar long-chain PFCA profiles in East Asian breast milk samples, as previously reported (Liu et al., 2010; Kim et al., 2011; Liu et al., 2011). A characteristic PFCA composition was observed for PFUnDA and PFTrDA (both odd-numbered PFCAs) with residual PFDoDA and PFDA (both even-numbered PFCAs). These findings indicated that odd-numbered PFCAs predominated over even-numbered PFCAs in East Asian breast milk samples. The PFCAs with longer chains than PFOA reached $47 \%$ of the total 
PFCAs for the average of the three countries. This finding suggests that infants are exposed to not only classical PFOA but also long-chain PFCAs in East Asia. Indeed, a factor analysis demonstrated two potential factors, F1 and F2, as sources of PFCAs. F1 had loading on medium-chain PFCAs, of which the factor score was significantly higher in Kyoto than in Beijing or Seoul. Kyoto is located in the Hanshin area, where there is a large emission source of PFOA and its related by-products (Niisoe et al., 2010). Thus, F1 may represent a local emission source of PFCAs. On the other hand, F2 had strong associations with long-chain PFCAs. The factor scores for F2 in the three large cities did not differ, suggesting that there are similar sources of long-chain PFCAs (>C10) in the three counties. Therefore, PFCA (C10-C13) biodegradation of FTOHs preferentially yields even-numbered PFCAs

346 (Fasanoa et al., 2009). Therefore, FTOHs are unlikely to be the main 
347 exposure source for Asian populations. Further investigations into the 348 sources and exposure routes are needed to predict the future trajectory of 349 these PFCA levels.

350 Although data concerning the PFC levels in human breast milk are not as 351 abundant as those in blood samples, we can still find several reports for 352 PFCs in human breast milk from Asia, the United States, and Europe. The related data are summarized in Table 6. In Japan, the PFOA levels in three regions were comparable (Tao et al., 2008; Nakata et al., 2009). In Korea, PFOA had a higher value in the present study compared with earlier research in Seoul (Kim et al., 2011) (mean: 63.8 vs. 41 pg $\mathrm{mL}^{-1}$, range: 14.7-172.1 vs. 21-77 pg $\mathrm{mL}^{-1}$ ). This increase may be consistent with the increasing trend in the PFOA level in serum samples by 1.27-fold from 2000 to 2007 in Korea (Harada et al., 2010).

In China, the concentrations of PFOA in Zhoushan ranged from 47 to 210 pg $\mathrm{mL}^{-1}$ (So et al., 2006) and in 12 different provinces of China, the mean PFOA level was 116 pg mL-1 (Liu et al., 2010). The PFOA levels showed large variations within China, although the other PFCAs were comparable among two previous studies and this study. In Southeast Asian developing countries, most of the milk samples did not contain detectable PFCAs (Tao et al., 2008), which might result from differences in industrialization. In the United States and European countries, PFOA and PFNA were detected in human breast milk samples, but long-chain PFCAs were not observed (Kuklenyik et al., 2004; Karrman et al., 2007; Bernsmann and Furst, 2008; Tao et al., 2008; 
370 Volkel et al., 2008; Karrman et al., 2010; Llorca et al., 2010). The occurrence

371 of long-chain PFCAs in East Asian countries is likely to be a fingerprint of 372 the sources of exposure.

Infant formulas were also evaluated in this study. The compositions of 374 PFCAs in the infant formulas were different from those in the breast milk samples. In Japan, the levels of PFCAs in the infant formulas were lower than those in the breast milk samples. These findings probably reflect differences in the bioaccumulation potential between humans and cows.

In our study, we found no evident relationships between the mother's characteristics and the PFCA concentrations. Although there were statistically significant differences for some of the PFCAs, no consistent trends were observed among the three countries.

The estimated daily intakes of PFOA were much lower than the TDI in this study. These observations may indicate that the health risks for PFOA intake from breast milk and infant formulas are limited. However, infants have different susceptibilities to adults with regard to their dynamic growth and developmental processes (Sly et al., 2008). In addition, the toxicokinetics and toxicities of long-chain PFCAs are still unclear, although these PFCAs comprised $48 \%$ of the total PFCAs in this study. These uncertainties necessitate more comprehensive toxicological studies on long-chain PFCAs, including PFOA.

The limitations of this study are the sample sizes and the sample selection method. It should be noted that these findings were based on a relatively 
small number of non-randomly selected volunteer samples. Moreover, the

394 sampling times for the Chinese donors were uncertain, although it is known

395 that the profiles of chemicals may change during the lactation period.

396 Considering these limitations, a future extended study is required for

397 confirmation of these findings,

398 In conclusion, various PFCAs were detected in human breast milk samples

399 from East Asian countries. Further studies are needed to evaluate the 400 exposure to long-chain PFCAs and the health risks in infants.

401

\section{Acknowledgments}

403 This study was mainly supported by Special Coordination Funds for 404 Promoting Science and Technology (No. 1300001) sponsored by the Japan 405 Science and Technology Agency, and a Grant-in-Aid for Health Sciences 406 Research from the Ministry of Health, Labour and Welfare of Japan 407 (H21-Food-003). The funding bodies had no roles in the study design, data 408 collection and analysis, decision to publish, or preparation of the manuscript. 409 The authors have no financial conflicts of interest. 
References

Bernsmann, T., Furst, P., 2008. Determination of perfluorinated compounds in human milk. Organohalogen Compd 70, 718-721.

EFSA, 2008 EFSA, Perfluorooctane sulfonate (PFOS), perfluorooctanoic acid (PFOA) and their salts, EFSA J 653 (2008), pp. 1-131.

EPA, U.S., 2006. 2010/15 PFOA Stewardship Program. http://www.epa.gov/oppt/pfoa/pubs/pfoastewardship.htm.

Fasano, W.J., Sweeney, L.M., Mawn, M.P., Nabb, D.L., Szostek, B., Buck, R.C., Gargas, M.L., 2009. Kinetics of 8-2 fluorotelomer alcohol and its metabolites, and liver glutathione status following daily oral dosing for 45 days in male and female rats. Chem Biol Interact 180, 281-295.

Fromme, H., Tittlemier, S.A., Volkel, W., Wilhelm, M., Twardella, D., 2009. Perfluorinated compounds--exposure assessment for the general population in Western countries. Int J Hyg Environ Health 212, 239-270.

Hansen, K., Johnson, H., Eldridge, J., Butenhoff, J., Dick, L., 2002. Quantitative characterization of trace levels of PFOS and PFOA in the Tennessee River. Environ Sci Technol 36, 1681-1685.

Harada, K.H., Koizumi, A., 2009. Environmental and biological monitoring of persistent fluorinated compounds in Japan and their toxicities. Environ Health Prev Med 14, 7-19.

Harada, K.H., Yang, H.R., Moon, C.S., Hung, N.N., Hitomi, T., Inoue, K., Niisoe, T., Watanabe, T., Kamiyama, S., Takenaka, K., Kim, M.Y., Watanabe, K., Takasuga, T., Koizumi, A., 2010. Levels of perfluorooctane sulfonate and perfluorooctanoic acid in female serum samples from Japan in 2008, Korea in 1994-2008 and Vietnam in 2007-2008. Chemosphere 79, 314-319.

Harada, K.H., Hitomi, T., Niisoe, T., Takanaka, K., Kamiyama, S., Watanabe, T., Moon, C.S., Yang, H.R., Hung, N.N., Koizumi, A., 2011. Odd-numbered perfluorocarboxylates predominate over perfluorooctanoic acid in serum samples from Japan, Korea and Vietnam. Environ Int 37, 1183-1189.

Haug, L.S., Thomsen, C., Becher, G., 2009. Time trends and the influence of age and gender on serum concentrations of perfluorinated compounds in archived human samples. Environ. Sci. Technol. 43, 2131-2136.

Ihaka, R., and R. Gentleman. 1996. R: a language for data analysis and graphics. J. Comp. Graph. Stat. 5:299-314. Available via http://www.R-project.org. 
Kärrman, A., Domingo, J.L., Llebaria, X., Nadal, M., Bigas, E., van Bavel, B., Lindstrom, G., 2010. Biomonitoring perfluorinated compounds in Catalonia, Spain: concentrations and trends in human liver and milk samples. Environ Sci Pollut Res Int 17, 750-758.

Kärrman, A., Ericson, I., van Bavel, B., Darnerud, P.O., Aune, M., Glynn, A., Lignell, S., Lindstrom, G., 2007. Exposure of perfluorinated chemicals through lactation: levels of matched human milk and serum and a temporal trend, 1996-2004, in Sweden. Environ Health Perspect 115, 226-230.

Kärrman, A., Harada, K.H., Inoue, K., Takasuga, T., Ohi, E., Koizumi, A., 2009. Relationship between dietary exposure and serum perfluorochemical (PFC) levels--a case study. Environ Int 35, 712-717.

Keller, J.M., Calafat, A.M., Kato, K., Ellefson, M.E., Reagen, W.K., Strynar, M., O'Connell, S., Butt, C.M., Mabury, S.A., Small, J., Muir, D.C., Leigh, S.D., Schantz, M.M., 2010a. Determination of perfluorinated alkyl acid concentrations in human serum and milk standard reference materials. Anal Bioanal Chem 397, 439-451.

Key, B., Howell, R., Criddle, C., 1997. Fluorinated organics in the biosphere. Environmental Science \& Technology 31, 2445-2454.

Kim, S.K., Lee, K.T., Kang, C.S., Tao, L., Kannan, K., Kim, K.R., Kim, C.K., Lee, J.S., Park, P.S., Yoo, Y.W., Ha, J.Y., Shin, Y.S., Lee, J.H., 2011. Distribution of perfluorochemicals between sera and milk from the same mothers and implications for prenatal and postnatal exposures. Environ Pollut 159, 169-174.

Koizumi, A., Harada, K.H., Inoue, K., Hitomi, T., Yang, H.R., Moon, C.S., Wang, P., Hung, N.N., Watanabe, T., Shimbo, S., Ikeda, M., 2009. Past, present, and future of environmental specimen banks. Environ Health Prev Med.

Koizumi, A., Yoshinaga, T., Harada, K., Inoue, K., Morikawa, A., Muroi, J., Inoue, S., Eslami, B., Fujii, S., Fujimine, Y., Hachiya, N., Koda, S., Kusaka, Y., Murata, K., Nakatsuka, H., Omae, K., Saito, N., Shimbo, S., Takenaka, K., Takeshita, T., Todoriki, H., Wada, Y., Watanabe, T., Ikeda, M., 2005. Assessment of human exposure to polychlorinated biphenyls and polybrominated diphenyl ethers in Japan using archived samples from the early 1980s and mid-1990s. Environ Res 99, 31-39.

Kuklenyik, Z., Reich, J.A., Tully, J.S., Needham, L.L., Calafat, A.M., 2004. Automated solid-phase extraction and measurement of perfluorinated organic acids and amides in human serum and milk. Environ Sci Technol 38, 3698-3704.

Lau, C., Butenhoff, J.L., Rogers, J.M., 2004. The developmental toxicity of perfluoroalkyl acids and their derivatives. Toxicol Appl Pharmacol 198, 231-241.

Liao, C., Wang, T., Cui, L., Zhou, Q., Duan, S., Jiang, G., 2009. Changes in Synaptic Transmission, Calcium Current, and Neurite Growth by Perfluorinated Compounds 
Are Dependent on the Chain Length and Functional Group. Environmental Science \& Technology 43, 2099-2104.

Liu, J., Li, J., Zhao, Y., Wang, Y., Zhang, L., Wu, Y., 2010. The occurrence of perfluorinated alkyl compounds in human milk from different regions of China. Environ Int 36, 433-438.

Liu, J., Li, J., Liu, Y., Chan, H.M., Zhao, Y., Cai, Z., Wu, Y., 2011. Comparison on gestation and lactation exposure of perfluorinated compounds for newborns. Environ Int 37, 1206-1212.

Llorca, M., Farre, M., Pico, Y., Teijon, M.L., Alvarez, J.G., Barcelo, D., 2010. Infant exposure of perfluorinated compounds: levels in breast milk and commercial baby food. Environ Int 36, 584-592.

Matsubara, E., Harada, K., Inoue, K., Koizumi, A., 2006. Effects of perfluorinated amphiphiles on backward swimming in Paramecium caudatum. Biochem Biophys Res Commun 339, 554-561.

Nakata, A., Saito, K., Iwasaki, Y., Ito, R., Kishi, R., Nakazawa, H., 2009. Determination of Perfluorinated Compounds in Human Milk and Evaluation of Their Transition from Maternal Plasma. BUNSEKI KAGAKU 58, 653-659.

Niisoe, T., Harada, K.H., Ishikawa, H., Koizumi, A., 2010. Long-term simulation of human exposure to atmospheric perfluorooctanoic acid (PFOA) and perfluorooctanoate (PFO) in the Osaka urban area, Japan. Environ Sci Technol 44, 7852-7857.

Olsen, G.W., Mair, D.C., Reagen, W.K., Ellefson, M.E., Ehresman, D.J., Butenhoff, J.L., Zobel, L.R., 2007. Preliminary evidence of a decline in perfluorooctanesulfonate (PFOS) and perfluorooctanoate (PFOA) concentrations in American Red Cross blood donors. Chemosphere 68, 105-111.

Prevedouros, K., Cousins, I.T., Buck, R.C., Korzeniowski, S.H., 2006. Sources, fate and transport of perfluorocarboxylates. Environ Sci Technol 40, 32-44.

Schecter, A., 1994. Dioxins and health. Plenum Press, New York

Sly, P. D. and Flack, F., 2008. Susceptibility of Children to Environmental Pollutants. Annals of the New York Academy of Sciences, 1140, 163-183.

So, M.K., Yamashita, N., Taniyasu, S., Jiang, Q., Giesy, J.P., Chen, K., Lam, P.K., 2006. Health risks in infants associated with exposure to perfluorinated compounds in human breast milk from Zhoushan, China. Environ Sci Technol 40, 2924-2929.

Steenland, K., Fletcher, T., Savitz, D.A., 2010. Epidemiologic evidence on the health effects of perfluorooctanoic acid (PFOA). Environ Health Perspect 118, 1100-1108.

Tao, L., Kannan, K., Wong, C.M., Arcaro, K.F., Butenhoff, J.L., 2008. Perfluorinated compounds in human milk from Massachusetts, U.S.A. Environ Sci Technol 42, 
3096-3101.

Tao, L., Ma, J., Kunisue, T., Libelo, E.L., Tanabe, S., Kannan, K., 2008. Perfluorinated compounds in human breast milk from several Asian countries, and in infant formula and dairy milk from the United States. Environ Sci Technol 42, 8597-8602.

Upham, B.L., Deocampo, N.D., Wurl, B., Trosko, J.E., 1998. Inhibition of gap junctional intercellular communication by perfluorinated fatty acids is dependent on the chain length of the fluorinated tail. Int J Cancer 78, 491-495.

Van Zelm, R., Huijbregts, M., Russell, M., Jager, T., Van de Meent, D., 2008. Modeling the environmental fate of perfluorooctanoate and its precursors from global fluorotelomer acrylate polymer use. Environmental Toxicology and Chemistry 27, 2216-2223.

Völkel, W., Genzel-Boroviczeny, O., Demmelmair, H., Gebauer, C., Koletzko, B., Twardella, D., Raab, U., Fromme, H., 2008. Perfluorooctane sulphonate (PFOS) and perfluorooctanoic acid (PFOA) in human breast milk: results of a pilot study. Int $\mathrm{J}$ Hyg Environ Health 211, 440-446.

von Ehrenstein, O.S., Fenton, S.E., Kato, K., Kuklenyik, Z., Calafat, A.M., Hines, E.P., 2009. Polyfluoroalkyl chemicals in the serum and milk of breastfeeding women. Reprod Toxicol 27, 239-245.

Wang, T., Wang, Y.W., Liao, C.Y., Cai, Y.Q., Jiang, G.B., 2009. Perspectives on the Inclusion of Perfluorooctane Sulfonate into the Stockholm Convention on Persistent Organic Pollutants. Environmental Science \& Technology 43, 5171-5175.

Wolf, C.J., Takacs, M.L., Schmid, J.E., Lau, C., Abbott, B.D., 2008. Activation of mouse and human peroxisome proliferator-activated receptor alpha by perfluoroalkyl acids of different functional groups and chain lengths. Toxicol Sci 106, 162-171. 

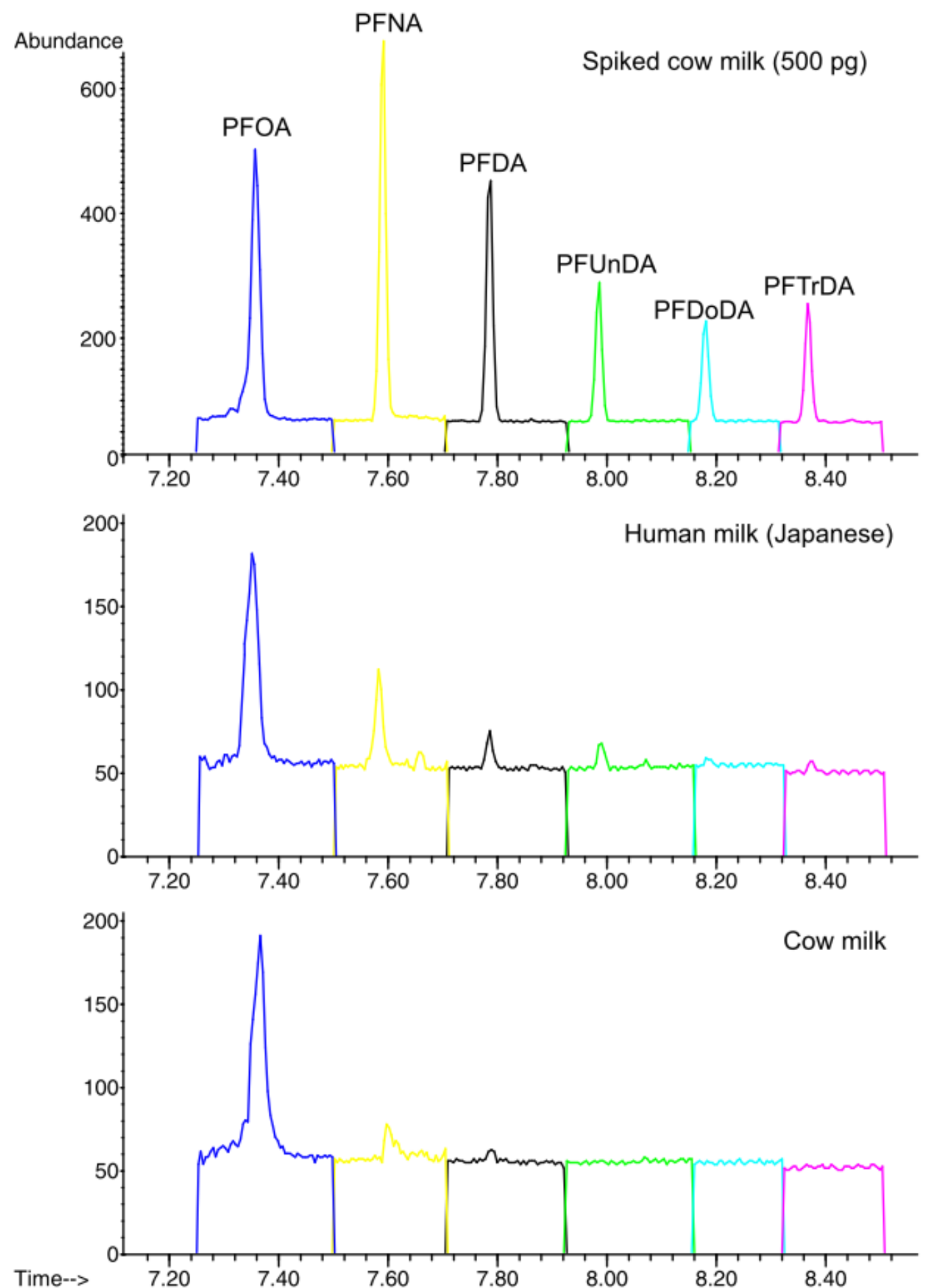

545 Supplemental figure 1.

546 Typical chromatograms of PFCAs obtained in this study. 
Table 1

Study areas and sample information.

a. Human milk

\begin{tabular}{|c|c|c|c|c|c|c|c|c|}
\hline Sampling site & $n$ & Year & Age $\left(\right.$ year) ${ }^{a}$ & (range) & $\operatorname{Parity}(n)$ & Smoking ${ }^{b c}$ & Drinking $^{\mathrm{C}}$ & Lactation period (week) ${ }^{a}$ \\
\hline Japan & & & & & & & & \\
\hline Kyoto & 30 & 2010 & $27.8 \pm 3.4$ & $(21-33)$ & $1(30)$ & Ex (7), non (23) & Ex(18), non(12) & $3.0 \pm 0.5$ \\
\hline Korea & & & & & & & & \\
\hline Seoul & 30 & 2010 & $30.9 \pm 2.3$ & $(26-36)$ & $1(22), 2(8)$ & Ex (3), non (27) & Curr(3), ex(2), non(25) & $1.6 \pm 1.1$ \\
\hline China & \multirow{2}{*}{\multicolumn{2}{|c|}{30 2008, 2009}} & & & & & & \\
\hline Beijing & & & $27.0 \pm 1.7$ & $(23-30)$ & $1(30)$ & Non (30) & Curr(2), ex(27), non(1) & NA \\
\hline
\end{tabular}

b. Infant formula

\begin{tabular}{cccc}
\hline Sampling site & $n$ & Year & $\begin{array}{c}\text { Targeted infant age } \\
\text { (month) }\end{array}$ \\
\hline $\begin{array}{c}\text { Japan } \\
\text { Kyoto }\end{array}$ & 5 & 2010 & $0-12$ \\
$\begin{array}{c}\text { China } \\
\text { Beijing }\end{array}$ & 4 & 2010 & $0-12$ \\
\hline
\end{tabular}

${ }^{\text {a }}$ Data are presented as the mean \pm standard deviation.

${ }^{\mathrm{b}}$ Including second-hand tobacco smoke.

${ }^{\mathrm{C} C u r r: ~ c u r r e n t ; ~ e x: ~ e x p e r i e n c e d ; ~ n o n: ~ n e v e r . ~}$ 


\section{Table 2}

Recoveries and detection limits for the PFCA analyses in human serum samples.

\begin{tabular}{|c|c|c|c|c|c|c|c|c|}
\hline \multirow[t]{2}{*}{ Compound } & \multirow{2}{*}{$\begin{array}{l}\text { Quantification } \\
\text { (confirmation) }\end{array}$} & \multirow{2}{*}{$\begin{array}{c}\text { Instrument detection } \\
\text { limit }^{\mathrm{a}}(\mathrm{pg}) \\
\end{array}$} & \multirow{2}{*}{$\begin{array}{l}\left.\text { Blank (pg mL }{ }^{-1}\right) \\
\text { range (mean) }\end{array}$} & \multirow{2}{*}{$\begin{array}{l}\text { Method detection } \\
\text { limit }^{\mathrm{b}}\left(\mathrm{pg} \mathrm{mL}^{-1}\right)\end{array}$} & \multirow{2}{*}{$\begin{array}{l}\text { Recovery and (reproducibility) } \\
\text { mean percentage (SD) }(n=9)\end{array}$} & \multicolumn{3}{|c|}{ Standard Reference Material $1954^{C}$} \\
\hline & & & & & & This study (pg g & U. Toronto ${ }^{\mathrm{d}}\left(\mathrm{pg} \mathrm{g}^{-1}\right)$ & Env. Canada ${ }^{\mathrm{d}}\left(\mathrm{pg} \mathrm{g}^{-1}\right)$ \\
\hline PFOA & $504(485)$ & 0.2 & $12.0-32.1(20.5)$ & 40 & 104(14) & 117 & 149 & 116 \\
\hline${ }^{13} \mathrm{C}_{4}$ PFOA & $508(489)$ & - & - & - & $99(12)$ & - & - & - \\
\hline PFNA & $554(535)$ & 0.2 & $<5-14.7(5.2)$ & 10 & $84(44)$ & 24 & 22 & $<16$ \\
\hline${ }^{13} \mathrm{C}_{5}$ PFNA & $559(540)$ & - & - & - & - & - & - & - \\
\hline PFDA & $604(585)$ & 0.2 & $<5-25.8(7.1)$ & 15 & $109(32)$ & 16 & 14 & $<6$ \\
\hline PFUnDA & 654 (635) & 0.5 & $<10$ & 10 & $95(45)$ & 12 & 7 & $<14$ \\
\hline PFDoDA & 704 (685) & 0.5 & $<10$ & 10 & $92(25)$ & $<10$ & 3 & $<8$ \\
\hline PFTrDA & $754(735)$ & 0.5 & $<10$ & 10 & $97(27)$ & $<10$ & - & - \\
\hline
\end{tabular}

Injection of $2 \mu \mathrm{L}$.

${ }^{\mathrm{b}}$ Milk sample of $2 \mathrm{~mL}$ (the mean blank signal was subtracted from the calculated sample concentration only if the calculated sample concentration was three times higher than the blank concentration).

${ }^{c}$ Milk standard reference material from the National Institute of Standards and Technology, 1954.

${ }^{\mathrm{d}}$ Analyzed by the University of Toronto and Environment Canada (Keller et al., 2010). 
Table 3

Concentrations of PFCAs in breast milk samples.

\begin{tabular}{|c|c|c|c|c|c|c|c|c|}
\hline \multirow{2}{*}{$\begin{array}{l}\text { Sampling } \\
\text { site }\end{array}$} & & \multicolumn{7}{|c|}{ Concentration $\left(\mathrm{pg} \mathrm{mL}^{-1}\right)$} \\
\hline & & PFOA & PFNA & PFDA & PFUnDA & PFDoDA & PFTrDA & $\Sigma$ PFCAs \\
\hline Japan & $n>\operatorname{MDL}(\%)$ & 28(93.3) & $27(90.0)$ & $20(66.7)$ & $28(93.3)$ & $5(16.7)$ & $10(33.3)$ & $30(100.0)$ \\
\hline \multirow{4}{*}{ Kyoto } & Median & $89(<40-194) A^{*}$ & $31(<10-72) A^{*}$ & $17(<15-65) A^{*}$ & $35(<10-100) A^{*}$ & $<10(<10-29)$ n.s. & $<10(<10-91) A B^{*}$ & $184(50.3-413.5) A^{*}$ \\
\hline & Mean & $93.5 \pm 43.7$ & $32.1 \pm 17.2$ & $21.3 \pm 15.0$ & $36.6 \pm 21.8$ & $<10$ & $15.2 \pm 20.6$ & $194.5 \pm 83.6$ \\
\hline & GM(GSD) & $82.7(1.7)$ & $26.5(2.0)$ & $16.9(2.0)$ & $30.4(2.0)$ & $<10$ & $<10$ & $176.7(1.6)$ \\
\hline & $\mathrm{P} 90$ & 173 & 62 & 44 & 65 & 22 & 36 & 315 \\
\hline Korea & $n>M D L(\%)$ & 24(80.0) & $20(66.7)$ & $4(13.3)$ & 22(73.3) & $4(13.3)$ & 15(50.0) & 28(93.3) \\
\hline \multirow[t]{4}{*}{ Seoul } & Median & $62(<40-173) \mathrm{B}^{*}$ & $15(<10-41) \mathrm{B}^{*}$ & $<15(<15-19) \mathrm{B}^{*}$ & $19(<10-51) \mathrm{B}^{*}$ & $<10(<10-41)$ n.s. & $10(<10-43) A^{*}$ & $114(<10-283.9) B^{*}$ \\
\hline & Mean & $64.5 \pm 33.7$ & $14.7 \pm 9.3$ & $<15$ & $19.6 \pm 13.1$ & $<10$ & $16.8 \pm 13.5$ & $118.8 \pm 50.9$ \\
\hline & GM(GSD) & $55.5(1.8)$ & $11.9(2.0)$ & $<15$ & $15.3(2.2)$ & $<10$ & $11.7(2.4)$ & $109.7(1.5)$ \\
\hline & P90 & 106 & 29 & 15 & 42 & 11 & 40 & 189 \\
\hline China & $n>M D L(\%)$ & 19(63.3) & $21(70.0)$ & $4(13.3)$ & 17(56.7) & $3(10.0)$ & $7(23.3)$ & $28(93.3)$ \\
\hline \multirow[t]{4}{*}{ Beijing } & Median & $51(<40-122) \mathrm{B}^{*}$ & $15(<10-47) \mathrm{B}^{*}$ & $<15(<15-29) B^{*}$ & $15(<10-47) \mathrm{B}^{*}$ & $<10(<10-25)$ n.s. & $<10(<10-43) \mathrm{B}^{*}$ & $84(<10-200.8) \mathrm{B}^{*}$ \\
\hline & Mean & $51.6 \pm 30.6$ & $15.3 \pm 9.6$ & $<15$ & $16.0 \pm 12.9$ & $<10$ & $<10$ & $87.8 \pm 54.9$ \\
\hline & GM(GSD) & $43.0(1.9)$ & $12.6(2.0)$ & $<15$ & $11.7(2.3)$ & $<10$ & $<10$ & $68.8(2.2)$ \\
\hline & P90 & 103 & 27 & 18 & 42 & 10 & 22 & 164 \\
\hline
\end{tabular}

MDL: method detection limit; GM: geometric mean; GSD: geometric standard deviation; P90: 90th percentile.

${ }^{*}$ Medians among different sites differ significantly $(p<0.05$, Steel-Dwass test). For example, the letters $A$ and $B$ indicate that the corresponding values differ significantly at $p<0.05$, while $A$ and $A$ or $B$ and $B$ indicate that the corresponding values do not differ significantly. 
Table 4

Factor analysis among PFCAs.

\begin{tabular}{ccccc}
\hline & Initial solution & \multicolumn{2}{c}{ Varimax rotated } \\
& $\mathrm{F} 1$ & $\mathrm{~F} 2$ & $\mathrm{~F} 1$ & $\mathrm{~F} 2$ \\
\hline Eigenvalue & 2.60 & 1.14 & & \\
Cumulative contribution (\%) & 43.3 & 62.3 & & \\
Eigenvector & & & & \\
PFOA & 0.387 & -0.511 & $\mathbf{0 . 8 1 8}$ & -0.135 \\
PFNA & 0.472 & -0.375 & $\mathbf{0 . 8 5 7}$ & 0.060 \\
PFDA & 0.480 & -0.020 & $\mathbf{0 . 6 6 8}$ & 0.390 \\
PFUnDA & 0.518 & 0.261 & $\mathbf{0 . 5 6 3}$ & $\mathbf{0 . 6 7 7}$ \\
PFDoDA & 0.114 & 0.430 & -0.086 & 0.488 \\
PFTrDA & 0.340 & 0.587 & 0.135 & $\mathbf{0 . 8 2 2}$ \\
\hline Factor score (mean $\pm S D)^{*}$ & & & & \\
& & Beijing & $-0.5 \pm 0.6^{\mathrm{B}}$ & $-0.2 \pm 0.7$ \\
& & Kyoto & $0.9 \pm 1.1^{\mathrm{A}}$ & $0.2 \pm 1.4$ \\
& & Seoul & $-0.4 \pm 0.6^{\mathrm{B}}$ & $0.1 \pm 0.8$
\end{tabular}

*Means among countries differ significantly $(p<0.05$, Steel-Dwass test). For example, the letters $A$ and $B$ indicate that the corresponding values differ significantly at $p<0.05$, while $A$ and $A$ or $B$ and $B$ indicate that the corresponding values do not differ significantly. 
Table 5

Concentrations of PFCAs in infant formulas.

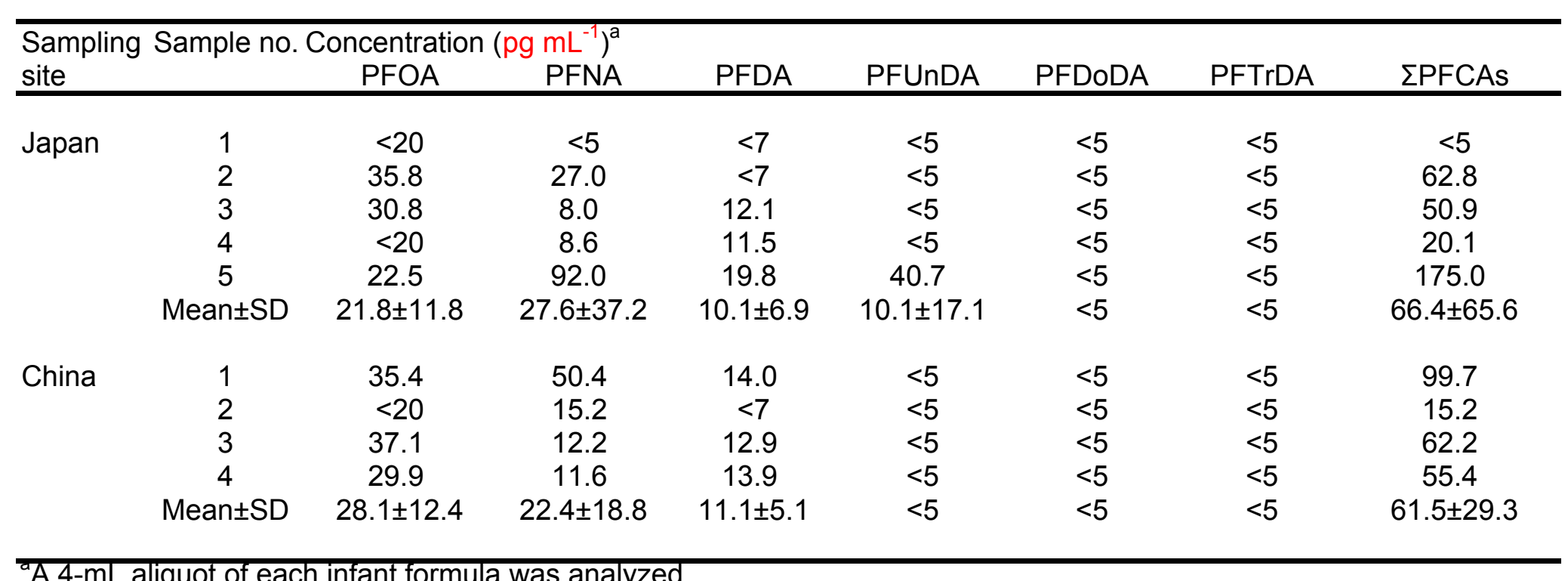

A 4-mL aliquot of each infant formula was analyzed. 
Table 6

Comparisons of the PFCA concentrations in human breast milk with reported data $\left(\mathrm{pg} \mathrm{ml}^{-1}\right)$

\begin{tabular}{|c|c|c|c|c|c|c|c|c|c|c|c|}
\hline Country & Region & Year & $n$ & & PFOA & PFNA & PFDA & PFUnDA & PFDoDA & PFTrDA & Reference \\
\hline \multirow[t]{3}{*}{ Japan } & Kyoto & 2010 & 30 & $\begin{array}{l}\text { Mean } \\
\text { Range }\end{array}$ & $\begin{array}{c}93.5 \\
<40-194\end{array}$ & $\begin{array}{c}32.1 \\
<10-72\end{array}$ & $\begin{array}{c}21.3 \\
<15-65\end{array}$ & $\begin{array}{c}36.6 \\
<10-100\end{array}$ & $\begin{array}{c}<10 \\
<10-29\end{array}$ & $\begin{array}{c}15.2 \\
<10-91\end{array}$ & This study \\
\hline & Hokkaido & NA & 51 & $\begin{array}{l}\text { Mean } \\
\text { Range }\end{array}$ & $\begin{array}{c}89 \\
<12-339\end{array}$ & $\begin{array}{c}35 \\
<4-150\end{array}$ & & & & & Nakata et al., 2009 \\
\hline & Ehime & 1999 & 24 & $\begin{array}{l}\text { Mean } \\
\text { Range }\end{array}$ & $\begin{array}{c}77.7 \\
<42.5-170\end{array}$ & $<8.82-23.9$ & & & & & Tao et al., 2008 \\
\hline \multirow[t]{2}{*}{ Korea } & Seoul & 2010 & 30 & $\begin{array}{l}\text { Mean } \\
\text { Range }\end{array}$ & $\begin{array}{c}64.5 \\
<40-173\end{array}$ & $\begin{array}{c}14.7 \\
<10-41\end{array}$ & $\begin{array}{c}<15 \\
<15-19\end{array}$ & $\begin{array}{c}19.6 \\
<10-51\end{array}$ & $\begin{array}{c}<10 \\
<10-41\end{array}$ & $\begin{array}{c}16.8 \\
<10-43\end{array}$ & This study \\
\hline & & 2007 & 17 & $\begin{array}{l}\text { Mean } \\
\text { Range }\end{array}$ & $\begin{array}{c}41 \\
<43-77\end{array}$ & $<8.8$ & $<18$ & $<24$ & $<13$ & & Kim et al., 2011 \\
\hline \multirow[t]{3}{*}{ China } & Beijing & $\begin{array}{l}2008- \\
2009\end{array}$ & 30 & $\begin{array}{l}\text { Mean } \\
\text { Range }\end{array}$ & $\begin{array}{c}51.6 \\
<40-122\end{array}$ & $\begin{array}{c}15.3 \\
<10-47\end{array}$ & $\begin{array}{c}<15 \\
<15-29\end{array}$ & $\begin{array}{c}16.0 \\
<10-47\end{array}$ & $\begin{array}{c}<10 \\
<10-25\end{array}$ & $\begin{array}{c}<10 \\
<10-43\end{array}$ & This study \\
\hline & Zhoushan & 2004 & 19 & $\begin{array}{l}\text { Mean } \\
\text { Range }\end{array}$ & $\begin{array}{l}106.3 \\
47-210\end{array}$ & $\begin{array}{l}18.1 \\
6.3-62\end{array}$ & $\begin{array}{l}7.2 \\
3.8-15\end{array}$ & $\begin{array}{c}19.1 \\
7.6-56\end{array}$ & & & So et al., 2006 \\
\hline & 12 provinces & 2007 & 1237 & $\begin{array}{l}\text { Mean } \\
\text { Range } \\
\text { (24 poo }\end{array}$ & $\begin{array}{c}116.0 \\
<14.15-814 \\
\text { led samples) }\end{array}$ & $\begin{array}{l}16.2 \\
6-76\end{array}$ & $\begin{array}{c}9.9 \\
<1.44-63\end{array}$ & $\begin{array}{c}37.6 \\
<1.30-196\end{array}$ & & & Liu et al., 2010 \\
\hline Vietnam & $\begin{array}{l}\text { Hanoi, Ho Chi } \\
\text { Minh }\end{array}$ & $\begin{array}{l}2000 \\
2001\end{array}$ & 40 & Range & $<42.5-89.2$ & $<8.82-10.9$ & & & & & Tao et al., 2008 \\
\hline Cambodia & Phnom Penh & 2000 & 24 & Range & $<42.5-132$ & $<8.82-12.3$ & & & & & Tao et al., 2008 \\
\hline Philippines & Quezon & $\begin{array}{l}2000 \\
2004\end{array}$ & 24 & Range & $<42.5-183$ & $<8.82-25.0$ & & & & & Tao et al. , 2008 \\
\hline Malaysia & Penang & 2003 & 13 & Range & $<42.5-90.4$ & $<8.82-14.9$ & & & & & Tao et al., 2008 \\
\hline Indonesia & $\begin{array}{l}\text { Jakarta, } \\
\text { Purwakarta }\end{array}$ & 2001 & 20 & Range & $<42.5$ & $<8.82-135$ & & & & & Tao et al., 2008 \\
\hline India & $\begin{array}{l}\text { Chidambaram, } \\
\text { Kolkata, Chennai }\end{array}$ & $\begin{array}{l}2002, \\
2004, \\
2005\end{array}$ & 39 & Range & $<42.5-335$ & $<8.82$ & & & & & Tao et al., 2008 \\
\hline \multirow[t]{2}{*}{ USA } & Unknown & 2003 & 2 & Range & $<200$ & & & & & & Kuklenyik et al., 2004 \\
\hline & Massachusetts & 2004 & 45 & $\begin{array}{l}\text { Mean } \\
\text { Range }\end{array}$ & $\begin{array}{c}43.8 \\
<30.1-161\end{array}$ & $\begin{array}{c}7.26 \\
<5.2-18.4\end{array}$ & & & & & Tao et al., 2008 \\
\hline Sweden & Uppsala & $\begin{array}{l}2004 \\
1996- \\
2004\end{array}$ & $\begin{array}{c}12 \\
9\end{array}$ & $\begin{array}{l}\text { Range } \\
\text { Range } \\
\text { (Pooled }\end{array}$ & $\begin{array}{c}<209-492 \\
<209 \\
\text { annual comp }\end{array}$ & $\begin{array}{c}<5-20 \\
<5-28 \\
\text { osite milk sa }\end{array}$ & $\begin{array}{r}\quad<8 \\
<8 \\
\text { imple) }\end{array}$ & $\begin{array}{l}<5 \\
<5\end{array}$ & & & Kärrman et al., 2007 \\
\hline \multirow[t]{2}{*}{ Germany } & NA & 2006 & 38 & $\begin{array}{l}\text { Range } \\
\text { (Archive }\end{array}$ & $\begin{array}{c}201-460 \\
\text { d samples }+1\end{array}$ & 9 fresh samp & les) & & & & Völkel et al., 2008 \\
\hline & $\begin{array}{l}\text { North Rhine } \\
\text { Westphalian }\end{array}$ & NA & 203 & Range & $25-610$ & & & & & & Bernsmann et al., 2008 \\
\hline Spain & $\begin{array}{l}\text { Tarragona } \\
\text { Barcelona }\end{array}$ & $\begin{array}{l}2007 \\
2008\end{array}$ & $\begin{array}{l}10 \\
20\end{array}$ & Range & $\begin{array}{c}<500 \\
<15.2-907\end{array}$ & $\begin{array}{l}<30 \\
<11.5\end{array}$ & $\begin{array}{c}<60 \\
<85.5-1095\end{array}$ & $<30$ & $<30$ & & $\begin{array}{l}\text { Kärrman et al., } 2010 \\
\text { Llorca et al., } 2010\end{array}$ \\
\hline
\end{tabular}


Supplemental Table 1

Correlations between PFCAs with different chain lengths.

\begin{tabular}{llcl}
\multicolumn{2}{l}{ Combination } & $\rho$ & $p$ value \\
\hline PFNA & PFOA & $\mathbf{0 . 4 1 8}$ & $<0.001$ \\
\hline PFDA & PFOA & 0.321 & 0.002 \\
PFDA & PFNA & 0.369 & $<0.001$ \\
\hline PFUnDA & PFOA & 0.359 & 0.001 \\
PFUnDA & PFNA & $\mathbf{0 . 4 7 5}$ & $<0.001$ \\
PFUnDA & PFDA & $\mathbf{0 . 4 2 2}$ & $<0.001$ \\
\hline PFDoDA & PFOA & -0.007 & 0.945 \\
PFDoDA & PFNA & 0.010 & 0.923 \\
PFDoDA & PFDA & 0.256 & 0.015 \\
PFDoDA & PFUnDA & 0.110 & 0.304 \\
\hline PFTrDA & PFOA & 0.094 & 0.377 \\
PFTrDA & PFNA & 0.082 & 0.443 \\
PFTrDA & PFDA & 0.031 & 0.769 \\
PFTrDA & PFUnDA & $\mathbf{0 . 4 7 8}$ & $<0.001$ \\
PFTrDA & PFDoDA & 0.151 & 0.156 \\
\hline$\rho:$ Spearman's correlation coefficient.
\end{tabular}




\section{Supplemental Table 2}

Associations between the PFCA concentrations and the participants' characteristics.

\begin{tabular}{|c|c|c|c|c|c|c|c|}
\hline \multicolumn{2}{|l|}{ Variables } & $\overline{P F O A}$ & PFNA & $\overline{\text { PFDA }}$ & $\overline{\text { PFUnDA }}$ & PFDoDA & $\overline{P F T r D A}$ \\
\hline \multicolumn{8}{|c|}{ Mother's age $(y r)^{a}$} \\
\hline \multicolumn{2}{|c|}{ Japan } & -0.056 & 0.054 & 0.014 & 0.328 & 0.371 & 0.384 \\
\hline \multirow{2}{*}{\multicolumn{2}{|c|}{$\begin{array}{l}\text { Korea } \\
\text { China }\end{array}$}} & 0.317 & 0.092 & 0.021 & 0.186 & $0.385^{*}$ & -0.156 \\
\hline & & -0.119 & $-0.421^{*}$ & 0.197 & -0.297 & 0.051 & -0.208 \\
\hline \multicolumn{8}{|c|}{ Child birth weight $(\mathrm{g})^{\mathrm{a}}$} \\
\hline \multicolumn{2}{|c|}{ Japan } & -0.104 & -0.017 & 0.101 & 0.174 & -0.017 & 0.107 \\
\hline \multirow{2}{*}{\multicolumn{2}{|c|}{$\begin{array}{l}\text { Korea } \\
\text { China }\end{array}$}} & -0.058 & -0.103 & 0.043 & 0.081 & -0.081 & 0.077 \\
\hline & & NA & NA & NA & NA & NA & NA \\
\hline \multicolumn{8}{|c|}{ Lactation period (wk) } \\
\hline \multicolumn{2}{|c|}{ Japan } & 0.125 & 0.104 & $0.474^{*}$ & 0.315 & -0.026 & -0.225 \\
\hline \multirow{2}{*}{\multicolumn{2}{|c|}{$\begin{array}{l}\text { Korea } \\
\text { China }\end{array}$}} & 0.088 & -0.044 & 0.181 & -0.121 & -0.193 & -0.107 \\
\hline & & NA & NA & NA & NA & NA & NA \\
\hline \multicolumn{8}{|c|}{ Fish intake $(\mathrm{g} / \mathrm{wk})^{\mathrm{a}}$} \\
\hline \multicolumn{2}{|c|}{ Japan } & -0.223 & -0.173 & -0.127 & -0.135 & 0.163 & 0.161 \\
\hline \multirow{2}{*}{\multicolumn{2}{|c|}{$\begin{array}{l}\text { Korea } \\
\text { China }\end{array}$}} & 0.098 & 0.026 & 0.314 & 0.133 & 0.072 & -0.023 \\
\hline & & NA & NA & NA & NA & NA & NA \\
\hline \multicolumn{8}{|l|}{ Smoking ${ }^{b}$} \\
\hline \multirow[t]{2}{*}{ Japan } & Non-smoker (23) & $101 \pm 45$ & $35 \pm 19$ & $24 \pm 16$ & $40 \pm 24$ & $9 \pm 8$ & $17 \pm 23$ \\
\hline & Others (7) & $69 \pm 28$ & $23 \pm 6$ & $12 \pm 7$ & $27 \pm 11$ & $5 \pm 0$ & $8 \pm 6$ \\
\hline \multicolumn{8}{|l|}{ Drinking ${ }^{b}$} \\
\hline \multirow[t]{2}{*}{ Japan } & Non-drinker (12) & $96 \pm 51$ & $36 \pm 16$ & $21 \pm 4$ & $30 \pm 15$ & $6 \pm 5$ & $6 \pm 3$ \\
\hline & Others (18) & $92 \pm 39$ & $30 \pm 18$ & $22 \pm 4$ & $41 \pm 25$ & $9 \pm 8$ & $21 \pm 25^{*}$ \\
\hline \multirow[t]{2}{*}{ Korea } & Non-drinker (25) & $61 \pm 27$ & $13 \pm 8$ & $8 \pm 4$ & $19 \pm 13$ & $7 \pm 7$ & $15 \pm 13$ \\
\hline & Others (5) & $83 \pm 58$ & $26 \pm 10^{* *}$ & $7 \pm 0$ & $22 \pm 14$ & $6 \pm 3$ & $25 \pm 13$ \\
\hline
\end{tabular}

${ }^{\mathrm{a}}$ For continuous variables, Spearman's correlation analysis was used for evaluations with the PFCA concentrations.

${ }^{\mathrm{b}}$ For categorical variables, the means were compared between two groups by the Mann-Whitney test. 


\section{Supplemental Table 3}

Daily intake estimations and hazard assessment for 1-year-old infants.

\begin{tabular}{|c|c|c|c|c|c|c|c|c|c|}
\hline \multirow{2}{*}{$\begin{array}{l}\text { Sampling } \\
\text { site }\end{array}$} & & & \multicolumn{7}{|c|}{ Estimated Intake $^{\mathrm{a}}$ (ng kg body weight $\left.{ }^{-1} \mathrm{~d}^{-1}\right)$} \\
\hline & & & PFOA & PFNA & PFDA & PFÚnDA & PFDoDA & PFTrDA & $\Sigma$ PFCAs \\
\hline \multirow{6}{*}{$\begin{array}{l}\text { Japan } \\
\text { Kyoto }\end{array}$} & Breast milk & Mean & 7.7 & 2.6 & 1.8 & 3.0 & 0.4 & 1.2 & 16.0 \\
\hline & & $\%^{\mathrm{b}}$ & $0.5 \%$ & - & - & - & - & - & - \\
\hline & & P90 & 14.2 & 5.1 & 3.6 & 5.3 & 1.8 & 3.0 & 25.9 \\
\hline & & $\%^{\mathrm{b}}$ & $0.9 \%$ & - & - & - & - & - & - \\
\hline & Infant formula & Mean & 1.8 & 2.3 & 0.8 & 0.8 & 0.2 & 0.2 & 5.5 \\
\hline & & $\%^{\mathrm{b}}$ & $0.1 \%$ & - & - & - & - & - & - \\
\hline \multirow{4}{*}{$\begin{array}{l}\text { Korea } \\
\text { Seoul }\end{array}$} & Breast milk & Mean & 5.3 & 1.2 & 0.6 & 1.6 & 0.4 & 1.4 & 9.8 \\
\hline & & $\%^{\mathrm{b}}$ & $0.4 \%$ & - & - & - & - & - & - \\
\hline & & P90 & 8.7 & 2.4 & 1.2 & 3.5 & 0.9 & 3.3 & 15.5 \\
\hline & & $\%^{b}$ & $0.6 \%$ & - & - & - & - & - & - \\
\hline China & Breast milk & Mean & 4.2 & 1.3 & 0.6 & 1.3 & 0.4 & 0.4 & 7.2 \\
\hline \multirow[t]{5}{*}{ Beijing } & & $\%^{\mathrm{b}}$ & $0.3 \%$ & - & - & - & - & - & - \\
\hline & & P90 & 8.5 & 2.2 & 1.5 & 3.5 & 0.8 & 1.8 & 13.5 \\
\hline & & $\%^{b}$ & $0.6 \%$ & - & - & - & - & - & - \\
\hline & Infant formula & Mean & 2.3 & 1.8 & 0.9 & 0.2 & 0.2 & 0.2 & 5.1 \\
\hline & & $\%^{b}$ & $0.2 \%$ & - & - & - & - & - & - \\
\hline
\end{tabular}

P90: 90th percentile.

${ }^{\mathrm{a}}$ The breast milk consumption rate and body weight for 1 -year-old infants were assumed to be $600 \mathrm{~g} \mathrm{~d}^{-1}$ and $7.3 \mathrm{~kg}$, respectively (Schecter, 1994).

${ }^{\mathrm{b}}$ Percent of the tolerable daily intake ( $1500 \mathrm{ng} \mathrm{kg}$ body weight ${ }^{-1} \mathrm{~d}^{-1}$ ) for PFOA by the Scientific Panel on Contaminants in the Food

Chain requested by the European Food Safety Authority in 2008 (EFSA, 2009). 